\title{
SÍNCOPE E ALÇAMENTO DA VOGAL POSTÔNICA NÃO-FINAL/O/: INDÍCIOS DE MOTIVAÇÃO EXTRALINGUÍSTICA
}

\author{
SYNCOPE AND RAISING OF THE POSTONIC NON-FINAL VOWEL /O /: INDICATION OF \\ EXTRALINGUISTIC MOTIVATION
}

\author{
Raquel Gomes Chaves \\ Doutoranda em Linguística pela Universidade de Santa Catarina \\ quelgchaves@gmail.com.br
}

Susiele Machry da Silva

Professora Assistente da Universidade Católica de Pelotas Doutora em Letras pela Pontifícia Universidade Católica do Rio Grande do Sul susiele@bol.com.br

\begin{abstract}
RESUMO: O presente artigo tem como objetivo estabelecer uma relação entre dois fenômenos fonológicos que atuam variavelmente sobre a vogal postônica não final $/ \mathrm{o} / \mathrm{em}$ palavras proparoxítonas: o de síncope da vogal (ávore árvre) e o de alçamento da vogal (árvore árvure). A metodologia empregada neste estudo fundamenta-se nos preceitos da Sociolinguística Variacionista (LABOV, 1972, 1994). São investigados dados fornecidos pelo banco VARSUL provenientes da fala de 14 sujeitos oriundos de Rincão Vermelho - RS, comunidade situada na zona de fronteira entre Brasil e Argentina. Os resultados sugerem que os fatores linguísticos que condicionam a manifestação dos processos são semelhantes e que a variável Escolaridade atua de forma significativa na aplicação de ambos os fenômenos.
\end{abstract}

PALAVRAS-CHAVE: Variação fonológica. Síncope. Alçamento. Vogal postônica não final /o/.

ABSTRACT: This paper aims at establishing a relationship between two phonological phenomena that act variably on non final postonic vowel /o/ in proparoxytones words: the syncope of the vowel (ávore árvre) and the raising of the vowel (ávore árvure). The methodology adopted by this study is based on the principles of the Variationist Sociolinguistics (LABOV, 1972, 1994). The data investigated here was provided by VARSUL database and corresponds to the speech of 14 subjects from Rincão Vermelho - RS, a community located on a border area between Brazil and Argentina. The results suggest that linguistic factors that influence the manifestation of both processes are similar, and that the Educational Level constraint acts significantly in the speakers' option by the application of both processes.

KEY WORDS: Phonological variation. Syncope. Raising phenomenon. Non final postonic vowel /o/.

\section{INTRODUÇÃO}

As vogais átonas do português, conforme aponta Câmara Jr. (2009[1979]), encontram-se mais vulneráveis à manifestação de processos do que as vogais tônicas, sobre as quais poucos fenômenos fonológicos incidem. De forma mais específica, as sete vogais do português (/a/, /ع/, /e/, /o/, /o/, /i/, /u/), distintivas na pauta tônica, perdem o caráter fonológico, em maior ou menor grau, nas pautas pretônica, postônica não final e postônica final. Em relação às vogais em posição postônica não final, dois processos possíveis de incidir sobre as vogais médias são o de síncope e o de alçamento. O processo de síncope da vogal postônica não final consiste no apagamento da vogal em formas como árvore arvre abóbra, cócega cosca. $\mathrm{O}$ alçamento, por sua vez, trata-se da neutralização vocálica resultante da elevação das vogais médias /e/ e /o/ como em árvore árvure, cócega cóciga. 
No que diz respeito à análise da atuação do processo de síncope da vogal postônica não final em dados de fala do PB, pode-se aludir aos trabalhos de Amaral (1999), Silva (2006), Lima (2008), Ramos (2009) e Chaves (2011). ${ }^{1}$ Os estudos referidos, apesar de investigarem dados de fala de diferentes regiões do Brasil, apresentam resultados bastante próximos quanto ao papel desempenhado pelos condicionadores linguísticos do processo. Mostram-se favoráveis à síncope: (a) as consoantes líquidas (lateral e vibrante) em contexto seguinte à vogal, (b) os fatores labial e velar, em contexto precedente à vogal; (c) a vogal dorsal /a/ e as vogais labiais /o/ e /u/. No que diz respeito ao condicionamento extralinguístico, os estudos revisados, em geral, têm indicado a variável Escolaridade como significativa ao apagamento: os informantes menos escolarizados são os que mais apresentarem maiores percentuais de síncope.

Com relação ao alçamento de vogais médias em posição não final, podem ser apontados os trabalhos de Schimitt (1987), Vieira (1994, 2002) e Machry da Silva (2009), pesquisas as quais analisaram o comportamento de vogais médias em posição postônica final e não final em regiões do Rio Grande do Sul. Apesar do envelope de variação ser distinto nas pesquisas citadas, verifica-se há consenso quanto aos fatores linguísticos que favorecem o alçamento da vogal postônica não final /o/: (a) as obstruintes labiais (p, b, f, v) e velares ( $\mathrm{k}, \mathrm{g}$ ), situadas em contexto precedente; (b) as consoantes labiais ( $\mathrm{p}, \mathrm{b}, \mathrm{f}, \mathrm{v}, \mathrm{m})$ e as líquidas $(/ \mathrm{l} / \mathrm{e} / \mathrm{r} /)$, localizadas em contexto seguinte. No que se refere à influência de fatores sociais sobre o alçamento, a variável Escolaridade apresenta papel relevante: os informantes mais escolarizados são os que tendem a elevar a vogal com maior frequência.

É possível perceber que, de acordo com os estudos que versam sobre os fenômenos de síncope e alçamento, ambos os processos são favorecidos por contextos linguísticos semelhantes: as consoantes labiais e velares situadas em contexto precedente foram destacadas como favoráveis à aplicação tanto da síncope quanto do alçamento; as líquidas localizadas em posição seguinte à vogal também foram apontadas como relevantes à manifestação dos dois processos. Da mesma forma, observou-se consonância nos resultados referentes aos fatores sociais: a variável Escolaridade foi indicada como significativa à atuação dos dois fenômenos, entretanto, os menos escolarizados foram referidos como os que mais produzem síncope, e, por outro lado, os mais escolarizados foram mencionados como os que mais realizam alçamento.

Com base nesse quadro, este estudo dedica-se a análise dos fenômenos fonológicos de síncope e alçamento nos dados que apresentam a vogal média /o/ na sílaba aludida, contexto suscetível à manifestação de ambos os processos. A partir desse objetivo geral, estipulam-se dois objetivos específicos: (i) identificar o papel das variáveis linguísticas na aplicação dos fenômenos em análise; (ii) verificar o papel das variáveis sociais na manifestação dos processos.

Apresentado o escopo de análise da presente pesquisa, torna-se necessário explicitar como o este artigo encontra-se organizado. Na seção 2, os procedimentos metodológicos empregados serão expostos. Na seção 3, os resultados serão divulgados e, por fim, as considerações finais a respeito dos resultados atingidos neste estudo serão exibidas.

\section{METODOLOGIA}

O estudo aqui proposto, vinculado à Sociolinguística Variacionista (LABOV, 1972, 1994), parte da análise de 14 entrevistas de experiência pessoal de falantes da comunidade de Rincão Vermelho - $\mathrm{RS}^{2}$, localidade situada na fronteira entre Brasil e Argentina. A estratificação dos informantes encontra-se expressa na Tabela 1 a seguir.

\footnotetext{
${ }^{1}$ Os trabalhos de Caixeta (1989) e Ximenes (2005) analisaram a manifestação do processo de apagamento conduzidos por outras abordagens linguísticas.

${ }^{2}$ Tais entrevistas, coletadas por Machry da Silva (2007), foram concedidas ao VARSUL- Agência PUCRS, e hoje integram a amostra complementar do banco.
} 
Tabela 1. Distribuição dos informantes por célula

\begin{tabular}{|c|c|c|c|c|c|c|}
\hline & \multicolumn{3}{|c|}{ Sexo Feminino } & \multicolumn{3}{|c|}{ Sexo Masculino } \\
\hline & $15-35$ & 36- 57 & 58 ou + & $15-35$ & $36-57$ & 58 ou + \\
\hline Ensino & 1 & 1 & 1 & 1 & 1 & 1 \\
\hline Ensino & 1 & 1 & 1 & 1 & 1 & 1 \\
\hline Médio & & & & & & \\
\hline $\begin{array}{c}\text { Ensino } \\
\text { Sunerior }\end{array}$ & 1 & & & 1 & & \\
\hline
\end{tabular}

Fonte: Adaptado de Machry da Silva (2009)

\subsection{Envelope de variação}

A variável dependente delimitada para este estudo considera: (i) alçamento, (ii) síncope, (iii) manutenção da vogal postônica não-final /o/. Dessa forma, as variantes que competem para a expressão da variável dependente são:

(i) alçamento da vogal postônica não-final /o/ (áv[u]re, fósf[u]ro)

(ii) síncope da vogal postônica não-final /o/ (árvre, fósfru)

(iii) manutenção da vogal postônica não-final /o/ (árv[o]re, fósf[o]ro)

As variáveis independentes linguísticas, delimitadas com base em estudos sociolinguísticos desenvolvidos sobre o alçamento e a síncope, encontram-se elencadas na Tabela 2 a seguir:

Tabela 2. Variáveis independentes linguísticas

\begin{tabular}{|c|c|c|}
\hline \multirow[t]{3}{*}{ Ambiente Precedente } & velar & cócoras \\
\hline & labial & árvore \\
\hline & coronal & agrônomo \\
\hline \multirow[t]{2}{*}{ Ambiente Seguinte } & oclusivo e nasal & éроса, ecônomo \\
\hline & líquido & fósforo \\
\hline
\end{tabular}

Fonte: Autoras

A partir da observação de que os contextos linguísticos que favorecem a aplicação da síncope e do alçamento são praticamente os mesmos, infere-se que a escolha do falante pela elevação ou pelo apagamento da vogal-alvo está relacionada a fatores de ordem social. Dessa forma, além das variáveis linguísticas, avalia-se também a atuação das variáveis independentes extralinguísticas exibidas na Tabela 3:

Tabela 3.Variáveis independentes extralinguísticas

\begin{tabular}{l|l}
\hline \multirow{2}{*}{ Sexo } & feminino \\
& masculino \\
\hline \multirow{2}{*}{ Faixa Etária } & de 15 a 35 anos \\
& de 36 a 57 anos \\
& mais de 57 anos \\
\hline Escolaridade & Ensino Fundamental \\
\cline { 2 - 2 } & Ensino médio \\
\hline & Ensino superior \\
\hline
\end{tabular}

Fonte: Autoras 
A hipótese assumida por este estudo é a de a variável Escolaridade atue como favorável à aplicação tanto da síncope quanto do alçamento. No entanto, espera-se que: (i) os informantes com maior grau de instrução apresentem índices superiores de alçamento da vogal e (ii) os informantes com menor grau de instrução mostrem percentuais inferiores de síncope da vogal.

\section{RESULTADOS}

Em virtude de o grupo das proparoxítonas ser reduzido em comparação ao das palavras de outras classes acentuais, o que significa que esta pesquisa se debruçou sobre um grupo lexical limitado, o número de dados passíveis de investigação tornou-se ainda mais restrito ao delimitarmos como foco de estudo apenas as proparoxítonas que apresentam a vogal postônica não final /o/. Desse modo, apesar de a investigação pautar-se no exame de dados de fala de 14 informantes, o número de proparoxítonas produzidas de acordo com esse critério foi de apenas 269. Em virtude da limitação do corpus, portanto, uma análise pautada apenas em índices percentuais será apresentada.

\subsection{Percentuais de aplicação}

Em um primeiro momento, foi realizada a computação estatística dos 269 casos em que os informantes investigados produziram proparoxítonas que apresentavam na sílaba postônica não final a vogal medial /o/. Os índices de aplicação dos processos de síncope e alçamento, assim como os de manutenção da vogal, encontram-se expressos no gráfico a seguir.

Gráfico 1. Frequência global de aplicação de síncope e alçamento

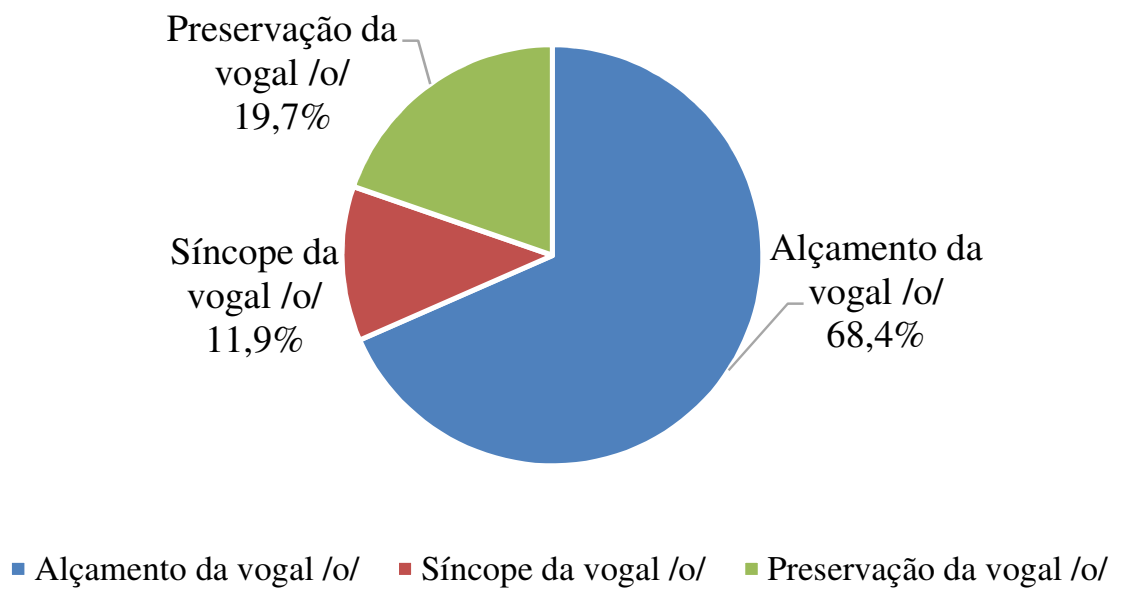

Fonte: Autoras

Conforme mostra o Gráfico 1, a preservação da vogal /o/ (abób[o]ra) foi observada em 19,7\% das proparoxítonas. Na maior parte dos dados em análise, a vogal postônica não-final /o/ sofreu a ação de algum processo: em $68,4 \%$ das proparoxítonas, a vogal /o/ foi alçada (épuca), e, em 11,9\% dos dados, a vogal foi elidida (fósfro). Foi verificado, em contrapartida, que o item lexical "época", encontrado em 91 ocorrências, havia sofrido o processo de alçamento da vogal postônica não final em 89 casos, ou seja, de forma praticamente categórica.

A fim de evitar um viés em função da alta taxa de aplicação do processo de alçamento concentrada em apenas no item lexical época, optou-se por excluir esses elementos do corpus em exame. Dessa forma, a amostra passou a contabilizar 178 dados. Com a exclusão da palavra 
"época", os índices de aplicação dos processos fonológicos em estudo sofreram alteração, como ilustra o gráfico subsequente.

Gráfico 2. Índice percentual de aplicação dos processos de síncope e alçamento da vogal /o/ - sem a computação dos dados do item lexical "época"

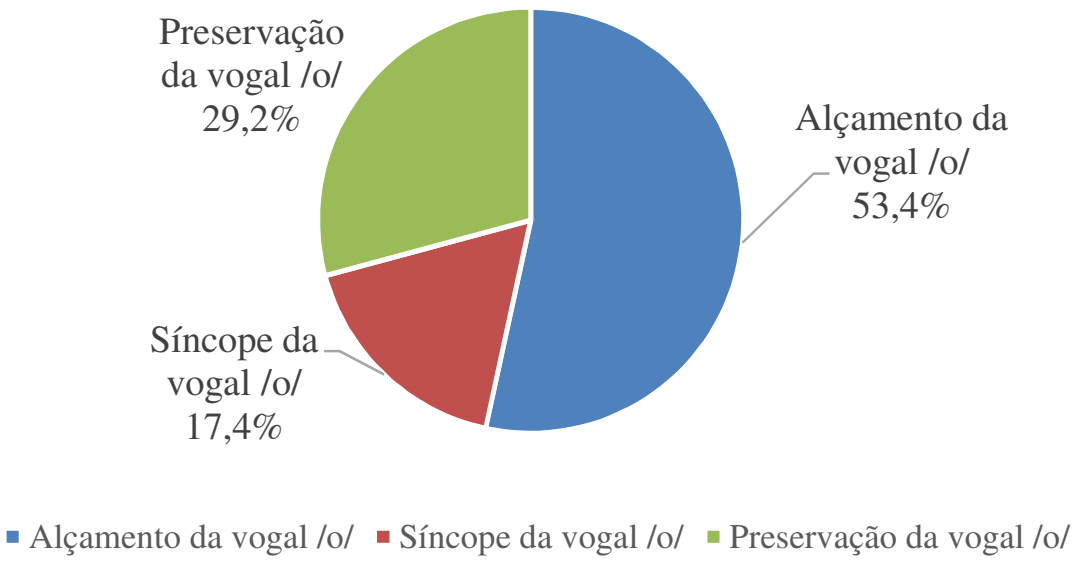

Fonte: Autoras

No Gráfico 2, os índices percentuais assumem os seguintes valores: preservação da vogal postônica não final $(29,2 \%)$, alçamento da vogal postônica não final $(53,4 \%)$ e síncope da vogal postônica não final $(17,4 \%)$.

\subsection{O papel das variáveis linguísticas}

A síncope, conforme mostra a tabela a seguir, manifestou-se, principalmente, quando a consoante anterior à vogal /o/ era uma labial, o que corresponde a cerca de $30 \%$ dos casos, resultado que segue a mesma direção dos estudos mencionados (Cf. Introdução). Entretanto, de forma divergente do que esses trabalhos têm relatado, a consoante velar não se mostrou favorecedora da aplicação do processo, ocorrendo em apenas $8,2 \%$ dos dados.

Tabela 4. Ambiente Precedente e Síncope

\begin{tabular}{l|cc}
\hline Fator & aplic/total & percentagem \\
\hline labiais & $25 / 87$ & $28,7 \%$ \\
velares & $5 / 61$ & $8,2 \%$ \\
coronais & $1 / 30$ & $3,3 \%$ \\
\hline
\end{tabular}

Fonte: Autoras

No que diz respeito ao processo de alçamento da vogal postônica /o/, observou-se também, de forma distinta aos relatos de estudos prévios sobre o fenômeno, que as consoantes coronais foram responsáveis pela maior taxa de aplicação do alçamento (80\%). Em seguida, mostraram-se como favorecedoras, as vogais velares em contexto precedente $(64 \%)$. 
Tabela 5. Ambiente Precedente e Alçamento

\begin{tabular}{l|cc}
\hline Fator & aplic/total & percentagem \\
\hline coronais & $24 / 30$ & $80 \%$ \\
velares & $39 / 61$ & $63,9 \%$ \\
labiais & $32 / 87$ & $36,8 \%$ \\
\hline
\end{tabular}

Fonte: Autoras

Apesar das divergências entre os resultados desta análise e daqueles exibidos por pesquisas anteriores, o ambiente precedente velar, como esperado, desempenhou papel favorável na manifestação de ambos os processos. O fator labial, apontado como relevante pelos estudos revisados, no entanto, não se mostrou, neste levantamento, relevante à aplicação do alçamento, o que se deve, provavelmente pela exclusão do item lexical "época", que computava 91 ocorrências do corpus.

A variável Ambiente Seguinte, por outro lado, revelou que tanto o processo de síncope quanto o processo de alçamento da vogal postônica medial /o/ tendem a sofrer influência das consoantes líquidas /l/ e /r/ situadas imediatamente após à vogal. A Tabela $6, \operatorname{logo}$ a seguir, revela os índices de aplicação do processo de síncope em relação ao ambiente subsequente.

Tabela 6. Ambiente Seguinte e síncope

\begin{tabular}{l|cc}
\hline Fator & aplic/total & percentagem \\
\hline líquidas & $28 / 132$ & $21,2 \%$ \\
obstruintes & $3 / 46$ & $6,5 \%$ \\
\hline
\end{tabular}

Fonte: Autoras

Conforme expresso na Tabela 6, a síncope foi verificada em maior proporção $(21,1 \%)$ nos dados que apresentavam uma consoante líquida na posição seguinte à vogal. O processo, no entanto, foi observado em apenas $6,5 \%$ das proparoxítonas que apresentavam uma obstruinte logo após a vogal-alvo.

Assim como no processo de síncope, as líquidas mostraram exercer influência também sobre o processo de alçamento da vogal postônica não-final /o/, como mostra a tabela a seguir.

Tabela 7. Ambiente Seguinte e alçamento

\begin{tabular}{l|cc}
\hline Fator & aplic/total & percentagem \\
\hline líquidas & $74 / 132$ & $56,1 \%$ \\
obstruintes & $21 / 46$ & $45 \%$ \\
\hline
\end{tabular}

Fonte: Autoras

De acordo com a Tabela 7, as líquidas sucederam as vogais postônicas alçadas em $56,1 \%$ dos dados. As obstruintes, todavia, apresentaram um percentual relativamente próximo no que diz respeito ao favorecimento do alçamento, equivalente a de $45 \%$. Assim sendo, em consonância com os resultados de estudos prévios, relatados no princípio deste artigo (cf. Introdução), no que diz respeito à variável Ambiente Seguinte, os dois processos, síncope e alçamento, indicam ser motivados pela presença das líquidas na posição adjacente a vogal-alvo. Tais resultados confirmam a hipótese, aventada por este estudo, de que tanto a síncope quanto o alçamento são fenômenos que se manifestam em contextos linguísticos semelhantes.

A partir da verificação de semelhanças no que tange à influência do ambiente linguístico sobre os fenômenos em exame, busca-se, na seção seguinte, investigar o papel das variáveis extralinguísticas no que diz respeito à escolha de uma variante em detrimento da outra. 


\subsection{O papel das variáveis extralinguísticas}

Em relação à variável Sexo, ambos os processos em estudo apresentaram, tanto para o sexo feminino quanto para o sexo masculino, taxas aproximadas de aplicação. Em relação à síncope, a diferença de manifestação do processo entre homens e mulheres foi de apenas 0,4 pontos percentuais $(17,6 \%$ - homens, $17,2 \%$ - mulheres $)$, como mostra a Tabela 8.

Tabela 8. Sexo e síncope

\begin{tabular}{l|cc}
\hline Fator & aplic/total & percentagem \\
\hline masculino & $15 / 85$ & $17,6 \%$ \\
feminino & $16 / 93$ & $17,2 \%$ \\
\hline
\end{tabular}

Fonte: Autoras

A diferença entre os percentuais masculinos e femininos também não se mostrou significativa no que se refere ao processo de alçamento da vogal postônica não final /o/. De acordo com a Tabela 9, apresentada a seguir, os homens aplicaram o processo de alçamento em cerca de $55 \%$ dos dados e, as mulheres, em aproximadamente $52 \%$, o que corresponde a uma diferença percentual de apenas 3,7 pontos.

Tabela 9. Sexo e alçamento

\begin{tabular}{l|cc}
\hline Fator & aplic/total & percentagem \\
\hline masculino & $47 / 85$ & $55,3 \%$ \\
feminino & $48 / 93$ & $51,6 \%$ \\
\hline
\end{tabular}

Fonte: Autoras

No que se refere à variável Faixa Etária, diferentemente do observado para a variável Sexo, a distribuição dos casos de ocorrência de síncope mostrou-se mais heterogênea. Os falantes com idade acima de 57 anos foram os que mais aplicaram o processo $(21,7 \%)$. Logo em seguida, os sujeitos mais jovens, com faixa etária entre 15 e 35 anos, aplicaram o fenômeno em 15,9\% dos dados e, por fim, os informantes da faixa etária intermediária, de 36 a 57 anos; foram aqueles que apresentaram menor índice de aplicação. Os resultados encontram-se organizados na Tabela 10.

Tabela 10. Faixa Etária e síncope

\begin{tabular}{l|cc}
\hline Fator & aplic/total & percentagem \\
\hline mais de 57 anos & $13 / 48$ & $27,1 \%$ \\
de 15 a 35 anos & $14 / 88$ & $15,9 \%$ \\
de 36 a 57 anos & $4 / 42$ & $9,5 \%$ \\
\hline
\end{tabular}

Fonte: Autoras

A variável Faixa Etária, na análise do processo de alçamento, também apresentou distribuição heterogênea entre os grupos etários controlados. No entanto, de forma distinta ao que foi observado na relação entre a variável Faixa Etária e manifestação do processo de síncope, os índices mais altos de aplicação do processo de alçamento foram verificados na faixa dos mais jovens $(63,6 \%)$. Os falantes mais velhos, com mais de 57 anos, apresentaram taxa de aplicação de $45,7 \%$, e os informantes com idade entre 36 e 57 anos, menor índice, equivalente a 40,5\%. 
Tabela 11. Faixa Etária e alçamento

\begin{tabular}{l|cc}
\hline Fator & aplic/total & percentagem \\
\hline de 15 a 35 anos & $56 / 88$ & $63,6 \%$ \\
mais de 57 anos & $22 / 48$ & $45,8 \%$ \\
de 36 a 57 anos & $17 / 42$ & $40,5 \%$ \\
\hline
\end{tabular}

Fonte: Autoras

As relações entre os processos de síncope e alçamento e as faixas etárias consideradas são ilustradas no Gráfico 3 a seguir.

Gráfico 3. Índice de aplicação de síncope e alçamento da vogal postônica não-final /o/ e Faixa Etária

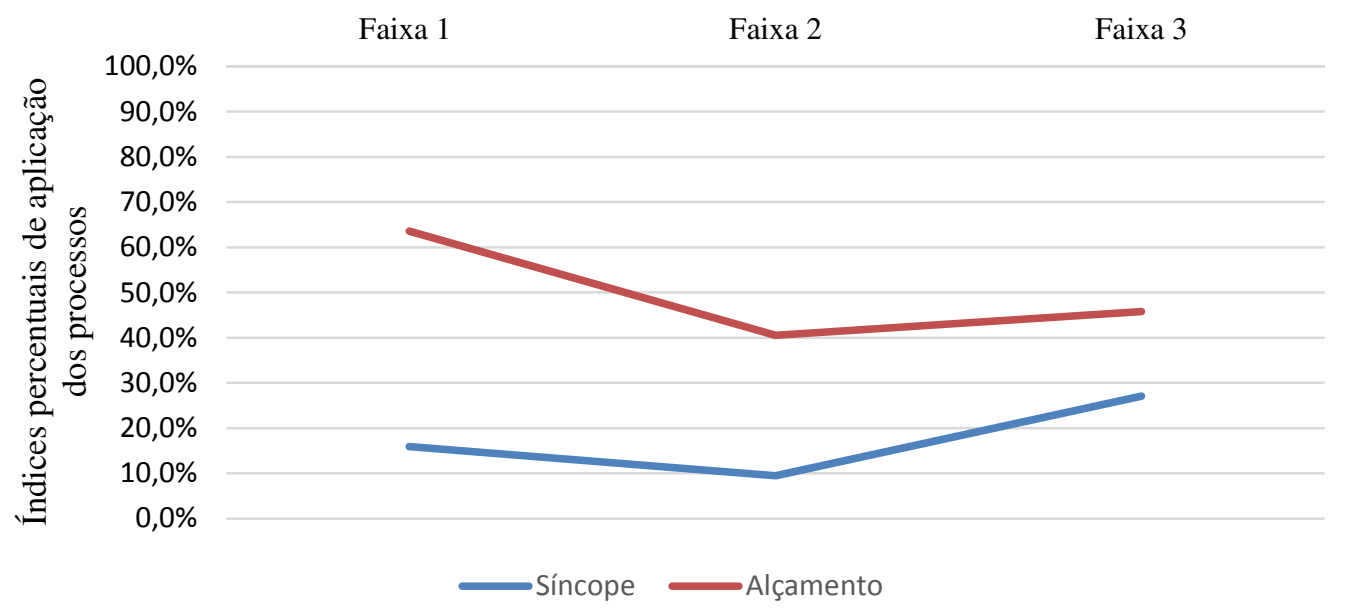

Fonte: Autoras

Diante dos resultados expressos no Gráfico 3, nota-se que todas as faixas etárias aplicam mais o alçamento do que a síncope, entretanto a Faixa 1, correspondente aos informantes de 15 a 35 anos, apresenta uma maior distância entre os percentuais, cerca de 50\%. Essa diferença percentual em relação à aplicação dos dois processos decresce à medida que a idade dos informantes aumenta: na Faixa 2, verifica-se uma diferença de aplicação em torno de $40 \%$ e, na Faixa 3, em torno de $20 \%$. Tais resultados parecem indicar que os falantes mais jovens mostram um comportamento linguístico polarizado, que ao mesmo tempo que favorece o alçamento, desfavorece a síncope. Em contrapartida, nos falantes mais velhos, embora ainda prevaleça a aplicação do alçamento, há também alta manifestação de síncope, o que reduz a configuração polarizada dos dados.

Dentre as variáveis extralinguísticas consideradas como dimensão de análise, a variável Escolaridade apresentou, como esperado, resultados bastante significativos. A presente análise, nesse sentido, vai ao encontro da maior parte dos estudos relativos ao PB que caracteriza a síncope como um fenômeno estigmatizado, característico, portanto, da fala de sujeitos com pouca ou nenhuma instrução formal. A tabela a seguir mostra o índice de manifestação do processo em relação ao grau de escolaridade dos informantes.

Tabela 12. Escolaridade e síncope

\begin{tabular}{l|cc}
\hline Fator & aplic/total & percentagem \\
\hline fundamental & $20 / 72$ & $27,8 \%$ \\
médio & $10 / 76$ & $13,2 \%$ \\
superior & $1 / 30$ & $3,3 \%$ \\
\hline
\end{tabular}

Fonte: Autoras 
Conforme indica a Tabela 12, os informantes com Ensino Fundamental aplicaram o processo de síncope em 27,8\% dos dados, os com Ensino Médio, em 13,2\% e, os com Ensino Superior, em apenas 3,3\% das proparoxítonas investigadas.

A relação entre o grau de instrução dos falantes e a atuação do processo de alçamento da vogal postônica não-final /o/ assume uma configuração completamente diferente da verificada na relação entre grau de escolaridade e síncope. Foram os informantes com maior grau de instrução os que mais produziram o fenômeno de alçamento. A Tabela 13 mostra os índices percentuais de aplicação em relação a cada um dos graus de escolaridade aferidos.

Tabela 13. Escolaridade e alçamento

\begin{tabular}{l|cc}
\hline Fator & aplic/total & percentagem \\
\hline superior & $24 / 30$ & $80,0 \%$ \\
médio & $41 / 76$ & $53,9 \%$ \\
fundamental & $30 / 72$ & $41,7 \%$ \\
\hline
\end{tabular}

Fonte: Autoras

Conforme a Tabela 13 demonstra, os informantes com Ensino Superior apresentaram um índice de aplicação de 80\% de alçamento, os sujeitos com Ensino Médio, taxa de 53,9\% e, por fim, os com Ensino Fundamental, índice de 41,7\%.

Com base nesses resultados, dois questionamentos surgem: (i) Os informantes menos escolarizados, que produzem mais síncope, seriam os mesmos que produzem em maior escala o processo de alçamento?; (ii) Os informantes mais escolarizados, com uma maior taxa de aplicação de alçamento, seriam aqueles que produzem, em menores índices, o processo de síncope? Partindo dessas duas indagações, decidiu-se, portanto, analisar o comportamento individual dos falantes quanto aos processos em exame.

A fim de ilustrar o comportamento individual referente aos processos analisados, organizouse um gráfico que ilustra as relações de aplicação de síncope e alçamento por informante em relação ao grau de escolaridade.

Gráfico 4. Índice de aplicação de síncope e alçamento da vogal postônica não-final /o/ por informante - grau de escolaridade ascendente

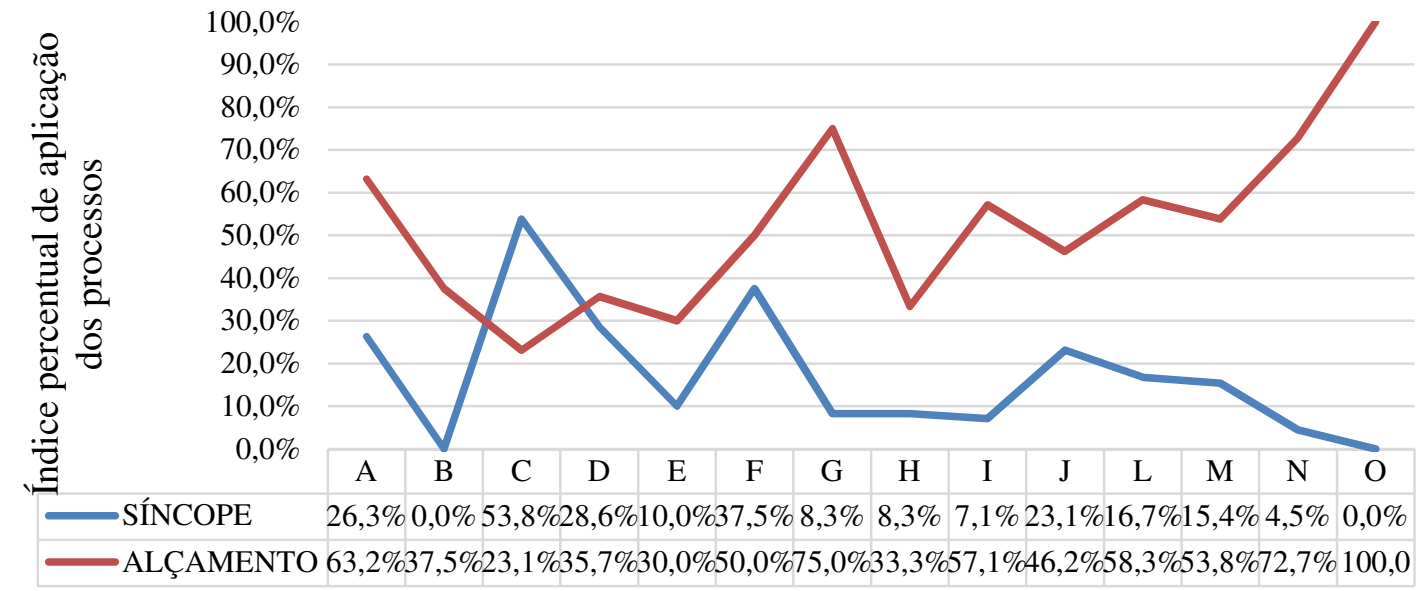

Fonte: Autoras

A partir da projeção visual é possível verificar uma relação entre a variável Escolaridade e os dois processos analisados. Em relação aos informantes com menor grau de escolaridade (do 
informante $\mathrm{A}$ ao F), não se observa uma correlação significativa entre os processos, visto que alguns informantes apresentam índices muito próximos de aplicação dos dois fenômenos (síncope e alçamento), enquanto outros sujeitos apresentam taxas de aplicação distantes. Nos valores apresentados pelos sujeitos com Ensino Médio (do informante G ao M), um padrão passa a ser verificado: as taxas de alçamento são superiores às de síncope nos dados de todos os informantes. Por fim, observa-se a mesma tendência na fala dos informantes com Ensino Superior, ou seja, os índices de aplicação dos processos tornam-se ainda mais acentuados em virtude da escolaridade (os sujeitos com maior grau de instrução apresentam taxas praticamente irrisórias do processo de síncope e, ao mesmo tempo, taxas bastante elevadas de alçamento).

Os resultados divulgados apresentam indícios de que: (i) assim como os estudos sobre a síncope da vogal postônica não final (AMARAL, 1999; SILVA, 2006; LIMA, 2008) têm indicado, a síncope trata-se de um fenômeno estigmatizado no PB; (ii) que há alguma indexação de prestígio agregada ao processo de alçamento no PB.

\section{CONSIDERAÇÕES FINAIS}

O presente artigo se propôs a estabelecer uma relação entre dois processos variáveis possíveis de incidir sobre a vogal média /o/ em posição postônica não final: o de síncope e o de alçamento. Em resposta às questões delineadas nos objetivos da presente pesquisa, verifica-se que: (i) os processos, assim como relatam estudos revisados, manifestam-se em ambientes linguísticos semelhantes, fato indicador de que a atuação das variáveis sociais seria relevante à manifestação de um processo em detrimento do outro; (ii) a variável Escolariadade desempenha papel significativo na aplicação de ambos os fenômenos - à medida que a escolaridade aumenta, a produção de síncope (fenômeno estigmatizado, claramente um estereótipo nos termos labovianos) diminui e, de forma distinta, a produção de alçamento torna-se mais elevada. Portanto, este estudo apresenta indícios de que a escolha do processo de síncope ou de alçamento em proparoxítonas é influenciada, na comunidade de Rincão Vermelho - RS, essencialmente pelo grau de instrução dos falantes.

\section{REFERÊNCIAS}

AMARAL, Marisa Porto do. As proparoxítonas: teoria e variação. Tese (Doutorado em Letras) Pontifícia Universidade Católica do Rio Grande do Sul. Porto Alegre, 1999.

ARAÚJO, Gabriel Antunes de. et. all. Algumas observações sobre as proparoxítonas e o sistema acentual do português. Cadernos de Estudos Linguísticos, v, 50, n. 1, p. 69-90, 2008. BUENO, Silveira. A formação histórica da língua portuguesa. 3. ed. São Paulo: Saraiva, 1967.

CAIXETA, Valmir. Descrição e análise da redução das palavras proparoxítonas.Dissertação (Mestrado em Letras) - Universidade Federal do Rio de Janeiro. Rio de Janeiro, 1989.

CHAVES, Raquel Gomes. A redução de proparoxítonos na fala do Sul do Brasil. Dissertação (Mestrado em Letras) - Pontifícia Universidade Católica do Rio Grande do Sul, Porto Alegre, 2011.

COUTINHO, Ismael de Lima. Gramática Histórica. Rio de Janeiro: Ao Livro Técnico, 1970

ILARI, Rodolfo. Linguística Românica. 3.ed. São Paulo: Ática, 2002.

LABOV, William. Padrões sociolingüísticos (Trad. de Marcos Bagno, Marta Maria Pereira Scherre, Caroline Rodrigues Cardoso). São Paulo: Parábola Editorial, 2008 [1972]. . Principles of Linguistic change. Volume II: Social Factors. Oxford:Blackwell, 1994.

LIMA, Giselly de Oliveira. O efeito da síncope de proparoxítonas: análise fonológica e 
variacionista com dados do sudoeste Goiano. Dissertação (Mestrado em Estudos Linguísticos) Universidade Federal de Uberlândia. Uberlândia, 2008.

CÂMARA JR., Joaquim Mattoso. Estrutura da Língua Portuguesa. 40. ed. Petrópolis: Vozes, 2009.

NUNES, José J. Compêndido de Gramática Histórica Portuguesa - fonética e morfologia. 7.

ed. Lisboa: Livraria Clássica Editora, 1969.

QUEDNAU, Laura. O acento do latim ao português arcaico. Tese (Doutorado em Letras) Pontifícia Universidade Católica do Rio Grande do Sul. Porto Alegre, 2000.

RAMOS, Adriana Perpétua. Descrições das vogais postônicas na variedade do noroeste paulista. Dissertação (Mestrado em Estudos Linguísticos) - Universidade Estadual paulista. São José do Rio Preto, 2009.

SCHMITT, Cristina Job. Redução Vocálica Postônica e Estrutura Prosódica. Dissertação (Mestrado em Letras) - Pontifícia Universidade Católica do Rio Grande do Sul. Porto Alegre, 1987.

SILVA, André Pedro da. Supressão da vogal postônica não-final: Uma tendência das

Proparoxítonas na Língua Portuguesa com Evidências na Falar Sapeense. Dissertação (Mestrado em Letras) - Universidade Federal da Paraíba. João Pessoa, 2006.

SILVA, Susiele Machry da. Elevação das vogais médias átonas finais e não finais no português falado em Rincão Vermelho - RS. Dissertação (Mestrado em Letras) - Pontifícia Universidade Católica do Rio Grande do Sul. Porto Alegre, 2009.

SILVA NETO, Serafim. História do latim vulgar. Rio de Janeiro: Livraria Acadêmica, 1957.

VIEIRA, Maria José Blascowski. Neutralização das vogais médias postônicas. Dissertação (Mestrado em Letras) - Pontifícia Universidade Católica do Rio Grande do Sul. Porto Alegre, 1994. . As vogais médias postônicas: uma análise variacionista. In: BISOL, Leda;

BRESCANCINI, Cláudia (Orgs.) Fonologia e variação: recortes do português brasileiro. Porto Alegre: EDIPUCRS, 2002.

WILLIAMS, Edwin. Do latim ao português. Rio de Janeiro: Tempo Brasileiro, 1973.

XIMENES, Luiza de Fátima Cabral. Estudo linguístico-histórico em Rio Verde: síncope e escolhas lexicais. Dissertação (Mestrado em Letras e Linguística) - Universidade Federal de Goiás. Goiânia, 2005.

Data de submissão: 26/03/2014

Data de aceite: 02/04/2015 